\title{
Respiratory Effects of Opioids in Perioperative Medicine
}

\author{
Chieh Yang Koo and Matthias Eikermann*
}

Critical Care Division, Mass General Hospital, Boston, MA, USA

\begin{abstract}
Opioids are widely used to treat acute and chronic pain as well as respiratory distress. There is great variability in opioid-induced side effects due to individual biological factors, patient co-morbidities and drug interactions. Normal respiratory rhythm generation is decreased primarily via inhibititory effects within the pre-Bötzinger complex. Central chemosensitivity to hypercapnia and hypoxia are blunted by opioids at the levels of the retrotrapezoid nucleus, medullary raphe nucles and nucleus tractus solitarius. Opioids also decrease central drive to both respiratory pump muscles and the upper airway dilator muscles. Opioid-induced respiratory depression can be reversed by naloxone, and recent data suggest that 5-HT4(a) agonists and ampakines are effective to reverse some of the opioid-induced respiratory depressant effects. The potentially fatal side effects of respiratory depression within the acute peri-operative setting necessitates effective monitoring of respiratory function in all patients receiving opioid therapy. Each institution needs to develop an optimal organization structure locally to define appropriate methods for avoiding medication errors, titrating opioids to target effect, and monitoring for respiratory side effects.
\end{abstract}

Keywords: Opioids, peri-operative, respiratory effects, upper airway, airway patency, safety, morphine.

\section{INTRODUCTION}

There are between 350,000 and 750,000 in-hospital cardiopulmonary arrests (IHCA) in the United States every year [1]. $80 \%$ of patients suffering an IHCA do not survive beyond hospital discharge and permanent anoxic brain injury is not uncommon amongst patients who survive [2]. Opioids are widely used in the intensive care unit (ICU) setting to treat pain and respiratory distress. The Society of Critical Care Medicine advocates the use of morphine as the drug of choice for pain management in mechanically ventilated patients [3]. A systematic review of 43 studies analyzing the use of opioids in patients in the intensive care unit concluded that the median morphine dose was $0.7 \mathrm{mg} / \mathrm{kg} / \mathrm{day}$ or approximately $49 \mathrm{mg} /$ day in a $70 \mathrm{~kg}$ patient [4]. However, opioids are known to cause respiratory depression and subsequent cardiopulmonary arrests. 24,157 post-operative patients in the post-anaesthesia care unit were shown to have a $1.3 \%$ risk of developing a critical respiratory event. Opioid pre-medication further increased this risk by 1.8 times [5].

Opioids are also frequently administered outside of the ICU setting such as within the emergency department and the general surgical wards. In the emergency department, a study showed that fentanyl was commonly administered prior to fracture or joint reduction. $1 \%$ of patients who received fentanyl within the emergency department had reported adverse events including respiratory depression and hypotension [6]. However, it is important to note that there is often great variability in the definitions of respiratory

*Address correspondence to this author at the Department of Anesthesia, Critical Care, and Pain Medicine, Massachusetts General Hospital and Harvard Medical School, 55 Fruit Street, Boston, MA, USA; Tel: 617-643-4408;

E-mail: meikermann@partners.org depression employed within various studies. These definitions can include the use of naloxone, hypoventilation as indicated by a decrease in respiratory rate, hypercarbia or oxygen desaturation. A review reported an incidence ranging from $0.3 \%$ to $17 \%$ of opioid-induced respiratory depression when such definitions were considered [7]. Two large reviews looking at 14,000 and 11,000 patients who received post-operative opioids via various routes of administration on the surgical wards reported respiratory depression at an incidence of $0.09 \%$ and $0.2 \%$ respectively $[8,9]$. However, most opioid administration within the surgical wards is via patient controlled analgesia (PCA). A standard regime would include a $1 \mathrm{mg}$ bolus dose followed by a 5 to 10 minute lockout period via the PCA device. This regime has repeatedly shown a low incidence of respiratory depression which ranges from $0.2 \%$ to $0.5 \%$ [10-13]. Although the incidence of opioid-induced respiratory depression is relatively low, these adverse events can occur within various clinical settings and are often life-threatening.

These fatal outcomes of opioid induced respiratory depression are well recognized. The most fatal events typically occur in the context of inadequate monitoring of the respiratory function. Deaths have been reported in patients with enlarged tonsils or upper airway tumours after selfadministration of morphine at home [14]. Children who were discharged home with codeine for post-adenotonsillectomy pain relief have died from respiratory depression. These children were found to have a mutation in the CYP2D6 enzyme which caused ultra-rapid codeine metabolism [15]. Near fatal respiration depression has also been reported in similar adults [16]. Clinically significant, but less dramatic side effects occur in perioperative patients in the hospital setting. Ten out of sixteen patients who received a morphine 
infusion post-operatively were reported to develop a total of 456 pronounced oxygen desaturation episodes $\left(\mathrm{SaO}_{2}\right.$ $<80 \%$ ) over an observation period of 16 hours. These desaturations typically occurred while the patient was asleep [17].

These examples of opioid induced respiratory depression highlight the fact that although clinicians are well aware of the potential dangers, there are still many reported occasions where patients are at risk to develop opioid-induced respiratory depression. Therefore, the widespread use of opioids in clinical practice emphasizes the importance of being vigilant in detecting potentially fatal adverse outcomes such as respiratory depression secondary to opioid administration.

\section{VARIBILITY OF OPIOID-INDUCED SIDE EFFECTS}

Opioid receptors have been well characterized through extensive studies. These receptors are a class of the seven transmembrane spanning G-protein coupled receptors. Opioid receptors have classically been divided into the three main subtypes of $\mu-, \kappa-$ and $\delta$-opioid receptors, and recent research has identified a fourth nociceptin receptor [18]. There is also evidence suggesting that opioids have effects on other receptors such as acetylcholine receptors. Fentanyl has been shown to attenuate the effect of acetylcholine through an inhibitory effect on muscarinic receptor activation to cause vasorelaxation [19].

The effects of opioids vary between individual patients due to a variety of factors. It is important to understand the variation in the extent of side effects observed clinically between patients. This is to minimize the potential risks to patients. These factors can be broadly classified under biological factors, co-morbidities and drug interactions with concurrent sedatives or hypnotics.

\section{Biological Factors}

These factors include intrinsic biological factors of the individual of which the individual is unable to change such as age, gender, ethnicity and other genetic factors. Older patients have been reported to have lower rates of clearance of morphine, codeine, fentanyl and oxymorphone [20]. Women also reportedly have up to $25 \%$ higher concentrations of oxycodone than compared to men [20]. The effects of opioids vary between genders as sex steroids may exert some influence over peripheral chemoreflexes [21]. The apnoeic threshold is affected by morphine in men but not in women, whilst morphine decreases the hypoxic sensitivity in women but not in men [22].

A variation in metabolism and clearance of opioids has been reported across various ethnic groups. There are higher clearance rates and therefore lower concentrations of morphine in Chinese patients both after administration of morphine or codeine [23]. Allelic variants of the gene which encodes for the cytochrome P450 enzyme CYP2D6 leads to altered rates of metabolism of opioids $[24,25]$. $7-10 \%$ of the Caucasian population have no functional CYP2D6 alleles and are therefore poor metabolizers. Conversely, $1-7 \%$ of Caucasians and greater than $25 \%$ of Ethiopians have gene duplications of the gene and metabolize opioids at a greatly increased rate [17]. Patients with increased metabolism of opioids run a greater risk of respiratory depression than poor metabolizers $[17,26]$.

\section{Patient Co-Morbidities}

Hepatorenal impairment is the most common comorbidity associated with altered opioid metabolism and excretion. Majority of opioid drugs are subjected to first-pass metabolism in the liver before entering the systemic circulation. Oxidation, hydrolysis and glucuronidation of opioids primarily occur in the liver. Increased peak levels and plasma concentrations of morphine, oxycodone and their respective active metabolites have been reported in patients with liver disease. This has been associated with an increased risk of adverse events [25, 27].

Most opioids are eliminated primarily through the urine [20]. The renal clearance of morphine, oxycodone and codeine metabolites is also reduced dramatically in patients with renal disease $[28,29]$. This subsequent accumulation of glucuronide metabolites has been reported to cause respiratory depression, [30] and should be avoided in patients requiring dialysis. This is important considering the high prevalence of patients on dialysis or in renal failure within the ICU setting who require pain or sedative medication. There have been case reports of oxycodone accumulation [31] and morphine-6-glucuronide accumulation from either morphine or codeine administration $[32,33]$ causing respiratory depression or arrest in patients with renal failure or requiring dialysis. Oxycodone has also been reported to have central nervous system toxicity effects in patients in renal failure [34].

However, not all opioids are affected by hepatorenal impairment. The pharmacokinetics of commonly used opioids such as fentanyl and methadone has been reported to be minimally affected by kidney or liver disease [35, 36].

Hypothermia has been shown to increase plasma fentanyl concentration [37]. This is clinically significant because therapeutic hypothermia is commonly used to improve outcomes after cardiac arrest and traumatic or ischaemic brain injury $[38,39]$. It is suggested that hypothermia can aggravate fentanyl overdose during continuous long-term administration in the ICU setting, resulting in more opioid-induced side effects and increasing the length of stay in the ICU [40]. Sleep apnoea is also greatly affected by administration of opioids and will be discussed in subsequent sections.

\section{Drug Interactions}

Many commonly used sedatives potentiate opioid induced respiratory depression. Propofol, when used in conjunction with remifentanil during the induction of anaesthesia, has been demonstrated to show a dose-dependent synergistic relationship, causing additive respiratory depression [41]. A similar additive relationship was observed between alfentanil and sevoflurane during anaesthesia [42]. Fentanyl also increased abdominal pressure and decreased end expiratory lung volume in patients anaesthetised with sevoflurane [43]. The result of this interaction between opioids and anaesthetic or sedative drugs may further exacerbate respiratory depression during the post-operative recovery phase [44]. Dexmedetomidine is gaining popularity as a sedative and anaesthetic agent due to a perceived lack of respiratory depression. However, there has been a case report of dexmedetomidine worsening respiratory depression when coadministered with opioids [45]. Drug addicts who are com- 
monly placed on buprenorphine for substitution treatment for heroin addiction occasionally abuse benzodiazepines concurrently. Concurrent use of buprenorphine and midazolam also causes additional respiratory depression [46].

\section{THE CONTROL OF RESPIRATION}

The goal of respiration is to maintain adequate oxygenation and removal of excess carbon dioxide. The respiratory rhythm is generated by the brainstem, and drives both the respiratory pump and accessory muscles such as the upper airway dilator muscles via spinal and cranial motoneurons [47]. (Fig. 1). Respiratory drive is modulated by feedback from central and peripheral chemoreceptors and is also driven in a feed-forward fashion by wake-active forebrain regions.

\section{Respiratory rhythm generation}

The respiratory cycle is comprised of three phases: inspiration, post-inspiration or passive expiration, and late or active expiration [48]. The respiratory rhythm driving these phases is believed to be generated in the pre-Bötzinger complex (Fig. 2). The pre-Bötzinger complex is located within the ventrolateral medulla $[49,50]$. It is comprised of neurons with rhythmogenic properties that play a primary role during inspiration [50]. These neurons rely on an intrinsic persistent sodium current dependent mechanism $\left(\mathrm{I}_{\mathrm{NaP}}\right)$ [50-52]. A subtype of rhythmogenic neurons which depend on either calcium or a calcium-activated non-specific and voltageindependent cation current $\left(\mathrm{I}_{\mathrm{CAN}}\right)$ may also exist $[53,54]$. All pre-Bötzinger neurons have an intrinsic $\mathrm{I}_{\mathrm{NaP}}$ and $\mathrm{I}_{\mathrm{CAN}}$ which contribute to the generation of inspiratory-related synaptic input. What is debatable is if these pacemaker neurons are solely responsible for the generation of the respiratory rhythm or if that they are part of a collective group pacemaker. It has been postulated that there are excitatory interconnections between pre-Bötzinger neurons which initiate positive feedback through recurrent excitation. The $\mathrm{I}_{\mathrm{NaP}}$ and $\mathrm{I}_{\text {CAN }}$ further activates the pacemaker neurons to amplify the overall inspiratory drive [49].

There is recent evidence supporting a secondary site within the medulla which can contribute to the respiratory rhythm under specific circumstances. A separate cluster of rhythmogenic expiratory-active neurons have been isolated within the vicinity of the retrotrapezoid nucleus (RTN) and parafacial respiratory group (pFRG) region - $(\mathrm{RTN} / \mathrm{pFRG})$ [55]. These neurons interact with the pre-Bötzinger complex as a coupled oscillatory system to regulate respiratory rhythm [56] (Fig. 2). RTN neurons respond to central $\mathrm{CO}_{2}$ (decreases in $\mathrm{pH}$ ) and provide excitatory drive to the preBötzinger complex [57]. Extensive studies have demonstrated that $\mu$ - and $\delta$-opioid receptors are also present in the respiratory regions of the pons and medulla [58-60].

The pre-Bötzinger complex is now believed to be the crucial site of action of opioids in respiratory depression as evidenced by a recently published study [61] (Fig. 2). There are inspiratory, expiratory and non-respiratory neurons within the pre-Bötzinger complex, with a sub-population of these neurons expressing neurokinin-1 receptors. (NK1R) Most of the NK1R-expressing pre-Bötzinger neurons are active during inspiration, and ARE preferentially inhibited by opioids. These NK1R-expressing neurons within the preBötzinger complex are the critical sites in mediating opioidinduced respiratory depression. Opioid administration to the pre-Bötzinger region expressing NK1R caused NK1R inhibition and resulted in respiratory rhythm arrest, abolished muscle activity and fatal apnoea unless reversed with naloxone. Another distinct region within the medulla innervated by pre-Bötzinger neurons was also identified which was highly associated with opioid-induced suppression of tongue muscle activity. This is in addition to the inhibitory effect of opioids on the hypoglossal motor neuron which is discussed subsequently, which results in potentially fatal upper airway obstruction.

There are other secondary feedback modulatory mechanisms affecting respiration. The Breuer-Hering reflex (BHR) terminates inspiration as a result of the action of pulmonary stretch factors, and primarily controls inspiratory-expiratory phase transitions. The BHR prevents the lung from overinflating, and a lack of BHR was shown to prolong inspiratory duration, decrease respiratory frequency and increase tidal volume [62]. Secondly, the Kölliker-Fuse (KF) nucleus and parabrachial complexes in the dorsolateral and ventrolateral pons can exert minor control over respiratory phase transitions during normal breathing. [62- 64]. Lalley demonstrated that $\mu$-opioid agonists on the KF nucleus and parabrachial complexes resulted in irregular respiratory patterns [65].

$\mu$-Opioid agonists have been shown thus far to decrease respiratory frequency and alter the normal rhythm of breathing. In his study, Pattinson demonstrated the effects of remifentanil on various cortical regions in the brain through functional magnetic resonance imaging [66]. Remifentanil

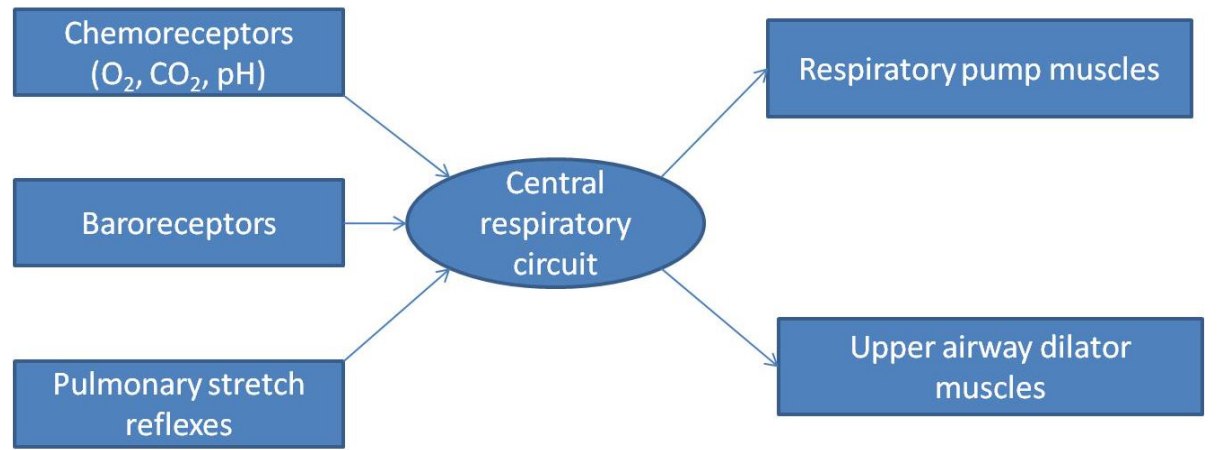

Fig. (1). Brief overview of the mechanics involved in control of respiration. 


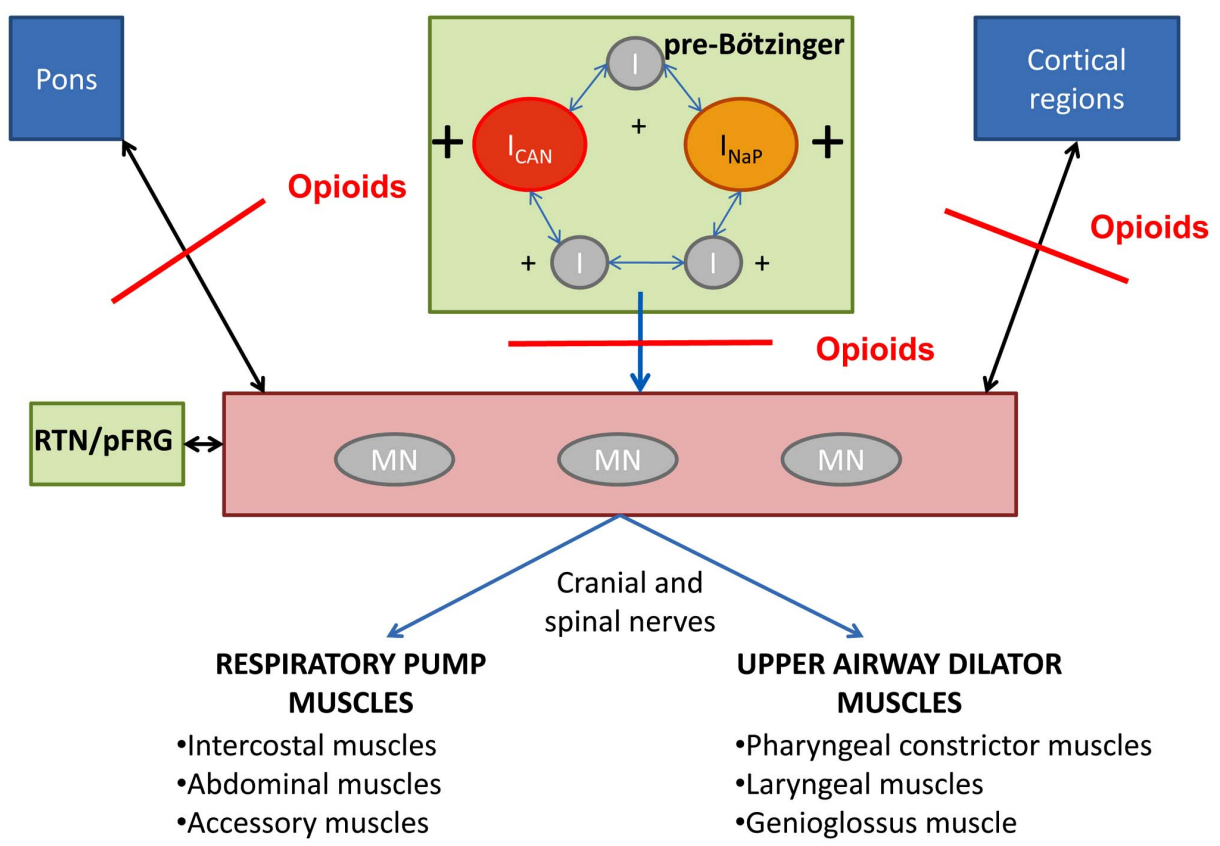

Fig. (2). Schematic diagram of respiratory circuitry. (blue arrows: excitatory, red lines: inhibitory) Although not shown, the RTN/pFRG (retrotrapezoid nucleus/parafacial respiratory group) and pons both affect breathing via strong, direct projections to the pre-Bötzinger complex. Rhythmogenesis is initiated within the pre- Bötzinger cells compromising of a network of excitatory neurons interconnected with $\mathrm{I}_{\mathrm{NaP}}$ and $\mathrm{I}_{\mathrm{CAN}}$ pacemaker cells which amplify the over excitatory synaptic drive to the various motoneurons (MN). Depending on the respiratory cycle phase, excitatory or inhibitory synaptic drive from the motoneurons are relayed to the respiratory pump muscles and the upper airway dilator muscles via the phrenic, vagus or hypoglossal nerve.

caused decreased activity in the bilateral insula and operculum, which was suggested to lead to a decrease in awareness of respiration through dampening of the response to hypercapnia. Thus, in addition to the brainstem origin of respiratory rhythm generation which is highly sensitive to the effects of opioids, certain cortical regions which appear to have a role in the modulation of respiration are similarly sensitive to opioids.

Finally, opioids may indirectly depress breathing by inhibiting brainstem arousal centers. For example, opioids inhibit acetylcholine release in the medial pontine reticular formation, and further contribute to unconsciousness by binding to opioid receptors in the periaqueductal gray, medulla and spinal cord to reduce noiciceptive transmission $[67,68]$. This sleep-like state induced by opioids further affect respiration as discussed subsequently in conjunction with obstructive sleep apnoea.

Opioid-induced respiratory depression is therefore primarily a result of the effect of opioids on NK1R-expressing pre-Bötzinger neurons, although the effect of opioids on various other central neuronal complexes may have an additional effect.

\section{Central and Peripheral Inputs}

There are many factors which mediate respiration. $\mathrm{CO}_{2}$ and $\mathrm{O}_{2}$ levels, $\mathrm{pH}$, blood pressure and other intrinsic reflexes are all able to influence respiration accordingly (Fig. 3). Any changes in these factors are detected by the chemoreceptors, baroreceptors and pulmonary stretch reflexes.

The chemoreceptors form the bulk of the input affecting respiratory drive. Chemoreceptors are both located within the central nervous system and peripherally in the carotid bodies (Fig. 3). The peripheral chemoreceptors primarily detect changes in $\mathrm{O}_{2}$ levels although they are also sensitive to $\mathrm{CO}_{2}$ levels [56]. It relays information regarding the partial pressure of $\mathrm{O}_{2}\left(\mathrm{P}_{\mathrm{O} 2}\right)$ to the nucleus tractus solitarius (NTS) via the carotid sinus branch of the glossopharyngeal nerve. [69] There are also major areas in the brain which are highly sensitive to $\mathrm{pH}$ and $\mathrm{P}_{\mathrm{CO} 2}$ levels. These are the central chemoreceptors [56]. The exact location of these chemoreceptors are still debatable but are currently thought to be located mostly in the brainstem including the retrotrapezoid nucleus (RTN), medullary raphe nucleus, nucleus tractus solitarius [70] and the locus coeruleus [71].

The RTN has been proposed to be the main site of central chemoreception. It consists of chemosensitive glutamatergic neurons that respond to changes in the partial pressure of $\mathrm{CO}_{2}\left(\mathrm{P}_{\mathrm{CO} 2}\right)$ by increasing tonic respiratory drive to the preBötzinger complex [72, 73]. The raphe nuclei have serotoninergic (5-HT) neurons which appear to be sensitive to changes primarily in intracellular $\mathrm{pH}$ rather than $\mathrm{P}_{\mathrm{CO} 2}$. These nuclei respond to an increase in intracellular $\mathrm{pH}$ by releasing neurotransmitters such as 5-HT, substance $\mathrm{P}$ and thyrotropin releasing hormone, causing excitatory changes within the respiratory network to increase ventilation [74, 75]. Results from various studies have also shown that different central chemoreceptor sites have different levels of sensitivities to changes in $\mathrm{P}_{\mathrm{CO} 2}$ levels during wakefulness and different stages of sleep [76, 77].

Sensory inputs from pulmonary and airway mechanoreceptors within the respiratory tract also influence respiration (Fig. 3). These pulmonary stretch reflexes travel within the vagus nerve to innervate the NTS, the pre-Bötzinger complex to alter rhythm generation, and the motoneurons within the ventral respiratory column to alter respiratory pattern. 


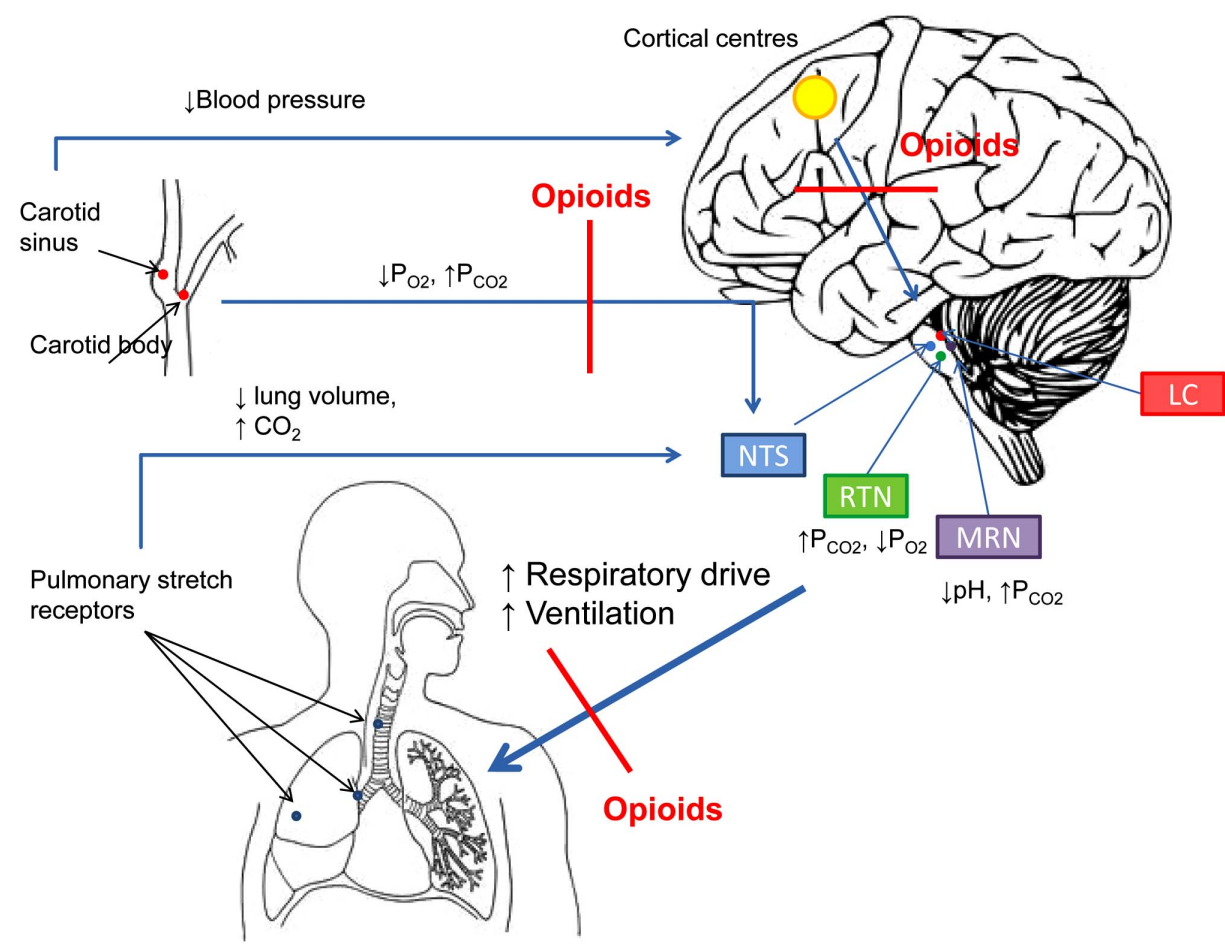

Fig. (3). Diagram illustrating the various afferent inputs from cortical regions, peripheral chemoreceptors, baroreceptots and pulmonary stretch receptors, as well as central chemoreceptors on respiratory drive and ventilation. The mechanisms of opiod-induced respiratory depression is marked in red.

Slowly adapting pulmonary stretch receptors are responsible for the Breuer-Hering reflex, which terminates inspiration and prolongs expiration as a protective response to increased lung volumes. Rapidly adapting irritant receptors are sensitive to chemical stimuli including $\mathrm{CO}_{2}$, of which stimulation results in rapid shallow breathing [69].

There is also suggestion that baroreceptor input may exert subtle influences on respiration, although its effects on blood pressure regulation are more recognized. Baroreceptors are located in the aortic arch and carotid sinuses, and respond to high blood pressure levels with increased synaptic firing. Baroreceptor activation has been shown to consistently suppress respiration through unclear pathways by prolonging expiratory duration, although its effects on inspiratory duration are more equivocal [78]. The strength of the baroreceptor input on respiration is dependent on age, [79] physical fitness [80] and the degree of arousal [81].

Chemoreceptors are essential because respiratory drive is driven primarily by hypercapnia. The ventilator response to hypoxia is thought only to be a vital backup reflex [82]. Ventilation is attenuated by responding to changes in the levels of carbon dioxide in the blood, which is sensed by the chemoreceptors to maintain eupnoeic breathing. A $1 \mathrm{mmHg}$ increase in $\mathrm{P}_{\mathrm{CO} 2}$ increases ventilation by around $20 \%$ to $30 \%$ [56]. Abnormal responses in ventilation to hypercapnia and hypoxia have been reported in patients on long-term methadone treatment causing central sleep apnoea [83]. Decreased central chemosensitivity to carbon dioxide has been reported in infants born to substance abusing mothers, and is thought to be a risk factor for the sudden infant death syndrome [84]. Similar impaired responses to hypercapnia and hypoxia have also been noted in acute opioid use [59].
Opioids decrease the ventilatory response to carbon dioxide [82] (Fig. 3). Local administration of a $\mu$-opioid agonist into the medullary raphe nucleus and NTS was shown to reduce its sensitivity to $\mathrm{P}_{\mathrm{CO} 2}$ changes causing decreased ventilation $[70,85]$. Opioids also have been demonstrated to impair the ventilator response to hypoxia [86]. Bailey suggested that the impaired response was mainly through the effect of opioids on the central nervous system over the peripheral chemoreceptors [82]. Local administration of morphine directly to the carotid bodies also resulted in a decrease in chemoreceptor discharge which was promptly reversed with naloxone [87].

$\mu$-Opioid agonists therefore affect chemosensitivity by blunting central chemosensitivity to hypercapnia and hypoxia, contributing towards respiratory depression.

\section{Respiratory Pump Muscles and Upper Airway Dilators}

The muscles involved in respiration can be classified into two main groups - the respiratory pump muscles and the upper airway dilators (Fig. 4). During inspiration, the thorax cavity expands as a result of contraction of the diaphragm and the external intercostal muscles. The lungs expand secondarily to the increased negative intra-thoracic pressure generated by these actions of the respiratory pump muscles. Inspiration is also affected by resistance to airflow. This resistance is predominately dependent on the patency of the upper airway dilator muscles, which include the muscles of the mouth, tongue and throat. Expiration at rest is usually passive, relying on the natural recoil of the lungs and ribcage back to their equilibrium position [56]. Active expiration recruits the abdominal muscles and the internal intercostal muscles, while active inspiration recruits other accessory muscles such as the scalene and the pectoralis muscles. 
Recent studies have examined the actions of the upper airway dilators more extensively, especially in relation to the pathogenesis of central and obstructive sleep apnoea. Patency of the upper airway is determined by an appropriate balance between dilating and collapsing forces. The upper airway collapses as a result of negative intra-luminal pressure generated by respiratory pump muscles during inspiration and the compressive extra-luminal forces exerted by surrounding tissue and bony structures. The actions of the pharyngeal muscle dilators and longitudinal traction exerted by the lung to a lesser extent help keep the upper airway patent [88] (Fig. 4).

The pressure required to collapse the airway is known as the critical closing pressure. $\left(\mathrm{P}_{\text {crit }}\right)$ [89] Patients with obstructive sleep apnoea have upper airways which collapse at higher pharyngeal pressures, or a less negative $\mathrm{P}_{\text {crit. }}$. It has been shown however, that negative intra-thoracic pressure alone reduces cross-sectional area and increases resistance to air flow, but does not cause complete collapse of the upper airway as long as the upper airway dilator muscles are active to antagonize the collapsing forces of the respiratory pump muscles. [90] Complete collapse typically requires extraluminal forces, which are a result of direct compression of the airway. Greater compressive forces are observed in obese patients due to the increased quantity of soft tissue around the airway [91]. The same effect can be observed in tissue and structures being crowded into a smaller bony compartment bordered by the mandible and the spinal column [92].

These collapsing forces are opposed by the actions of the pharyngeal dilator muscles. There are several dilator muscles involved including the tensor palatini muscle, although the most extensively studied muscle is the genioglossus muscle. These muscles are predominately activated during inspiration [93]. The hypoglossal motoneuron innervates the genioglossus muscle, which is responsible for both depression and protrusion of the tongue [94]. This depression and protrusion of the tongue increases the size and decreases the collapsibility of the upper airway $[95,96]$. It is an important dilator of the pharynx and therefore any decrease in genioglossal activity or other upper airway dilator muscle activity will decrease pharyngeal patency [97]. Post-operative patients have an increased risk of upper airway collapse during extubation due to the impairment of genioglossal muscle activity, highlighting the importance of the genioglossus muscle [98].

It is the inability to maintain upper airway patency which is central in the pathogenesis of obstructive sleep apnoea [88]. The airways in such patients are narrower and therefore elicit strong compensatory reflexes which activate dilator muscles to maintain patency during wakefulness. The activity of the genioglossus muscles is however inhibited by sleep, which ultimately leads to the collapse of the upper airway [99].

Opioids suppress hypoglossal activity by disinhibiting cholinergic neurotransmission within the hypoglossal nucleus [49]. White also suggested that opioids diminish the responsiveness of the upper airway muscles to hypercapnia in addition to its effects on decreasing respiratory drive [97]. $\mathrm{He}$ also suggested that chronic opiate consumption may have a different effect on pharyngeal dilator muscle activity of unknown mechanism compared to acute opioid usage through his observation of chronic pain patients on long term opioids. Hajiha investigated the effects of $\mu$-opioid agonist fentanyl at the hypoglossal motoneuron, which demonstrated significant suppression of genioglossus activity [100]. Stimulation of $\delta$-opioid receptors at the hypoglossal motoneuron also resulted in similar suppression of activity. However, to our knowledge, the effect of opioids on upper airway dilator muscle control has not been studied rigorously in patients.

The effect of opioids on respiratory muscles extends beyond that of the genioglossus muscle. $\mu$-Opioids lead to tonic

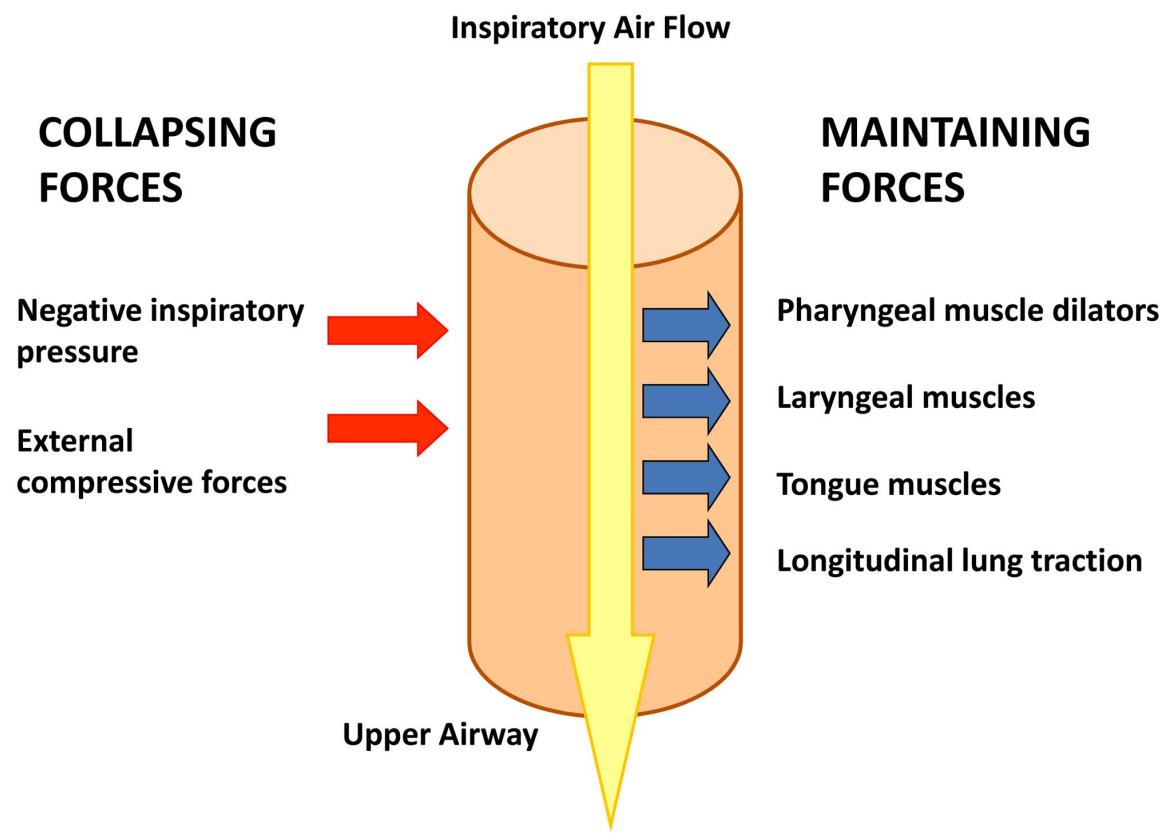

Fig. (4). Schematic diagram showing the various forces acting on the upper airway controlling its patency. Maintenance of the upper airway patency is dependent on the balance between the opposing forces as illustrated. 
firing of laryngeal adductor motoneurons and low frequency discharges within the vagal laryngeal abductor and pharyngeal constrictor motoneurons. This results in increased upper airway resistance, and is suggested to be the reason behind vocal fold closure and pharyngeal airflow obstruction seen with $\mu$-opioids [101]. Opioid receptors have also been described within the lower bronchioles and alveoli [102]. The administration of opioids has been demonstrated to cause an increase in pulmonary resistance [103]. This has been attributed to the opioid cholinergic action on smooth muscle causing increased bronchoconstriction. Chest wall compliance was also noted to be decreased with opioids. This is consistent with previous studies which have reported increased chest wall muscle tone causing impaired ventilation [104]. Abdominal muscle rigidity has also been shown with highdose opiates, [105] and is also associated with decreased phrenic nerve and diaphragmatic muscle activity. This reduces tidal volume and minute ventilation and contributes towards respiratory depression [106].

Opioids affect both respiratory pump muscles and the upper airway dilator muscles. Chest wall compliance and diaphragmatic muscle activity decrease with opioid usage. Upper airway resistance also increases as a result of the effects of opioids on the genioglossus, laryngeal muscles and the pharyngeal constrictors.

\section{OPIOIDS IN OBSTRUCTIVE SLEEP APNOEA}

Obstructive sleep apnoea is characterized by repetitive partial or complete upper airway obstruction, causing cessation of breathing during sleep resulting in repetitive arousal from sleep to restore airway patency [107]. There is data to suggest that the effects of anaesthesia on upper airway dilator muscle control are similar to the effects of sleep [108]. The pathophysiology of obstructive sleep apnoea in relation to the respiratory effects of opioids has been discussed in previous sections. It is therefore pertinent to highlight the risks of opioid administration in patients with obstructive sleep apnoea, who are known to be at greater risk of respiratory depression.

There must be judicious use of opioids in patients with obstructive sleep apnoea. These patients report greater number of adverse events with opioid administration when compared with the general population. Oral hydromorphone does not cause a significant increase in apnoeic or hypopnoea episodes in healthy patients. However, patients who reported a higher baseline of obstructive events also reported a greater number of apnoeic episodes with high doses of hydromorphone [109]. Another study showed that children with nocturnal desaturations can develop chronic hypoxemia during sleep, which upregulates central opioid receptors. These children are more sensitive to opioid effects and require only half the usual dosage of analgesia opiates used in healthy children [110]. Although there is less evidence in adults with obstructive sleep apnoea, there have been numerous case reports describing respiratory and cardiac arrests leading to death [111- 114]. The American Society of Anaesthesiologists has recently issued practice guidelines for the perioperative management of patients with obstructive sleep apnoea to reduce the risk of adverse outcomes, including recommendations regarding opioid administration [115].
However, there is still insufficient evidence regarding perioperative management of patients with obstructive sleep apnoea [107].

\section{SAFETY OF OPIOID THERAPY IN THE PE- RIOPERATIVE SETTING}

The potentially fatal side effect of respiratory depression in opioids within the acute peri-operative setting necessitates effective clinical monitoring.

The risks of respiratory depression with opioids are small but severe. Two retrospective reviews comprising of more than one thousand patients reported a $1 \%-2 \%$ risk of developing post-operative respiratory depression with morphinebased patient-controlled analgesia. This respiratory depression extended to 31 hours after initiation of analgesia, highlighting the importance of both short-term and long-term patient monitoring [116, 117].

Studies are equivocal over the incidences of respiratory depression in PCA and conventional techniques. However, occasional overdoses in patients using PCA have raised safety concerns. One of the main reasons for the adverse reactions has been incorrect programming of the PCA pump. Common programming errors include: delivering a bolus dose and failing to return the pump settings to the correct rate, confusing "milligram" and "milliliter", selecting the wrong lockout, selecting the wrong drug concentration, confusing "PCA bolus dose" with "PCA basal dose" or "PCA continuous infusions".

It should also be pointed out that patients with specific co-morbifities such as central sleep apnoea are also at greater risk for developing hypercarbia and apnoeic episodes with post-operative opioid pain relief $[44,118]$.

\section{Monitoring Opioid Therapy}

Monitoring patients' respiratory function is an essential part of opioid therapy, particularly when initiating an opioid therapy in opioid naïve patients. Physicians working on surgical wards are often reluctant to administer opioids intravenously or via an epidural catheter, because continuous monitoring of the respiratory function during the time required to titrate the dose to the desired effect is not typically possible in this scenario. However, several studies have repeatedly shown that opioids given via various routes can be safely administered within the general surgical wards with low rates of reported adverse effects and without the need for special monitoring equipment. Established nursing routines included regular measurements of pain scores, heart rate, respiratory rate, blood pressure, sedation levels 1 to 2 hourly within the first 12 to 24 hours, before decreasing in frequency to 4 to 8 hourly observations. The incidence of side effects was low and adverse effects were picked up by the nursing staff when evident [119-121].

However, there have been several case reports on 'silent death' after opioid administration in patients at risk of developing respiratory complications. These patients die silently without dyspnoea without alerting their nurses. This raises many questions: How do we define patient populations who are at an increased risk to develop opioid-induced respiratory depression? How should we manage peri-operative opioid 
therapy in patients at risk? Is intravenous PCA safer than oral administration of a standard dose? How should we monitor respiratory function outside of the recovery room and ICU? Do we need to invest in objective monitors to assess $\mathrm{SpO}_{2}$ or respiratory rate continuously? We believe that this may possibly be the case.

Since including pain management in the Joint Commission standards in 2001, the Commission has focused on these areas: adequate pain management, pain assessment, drug use, and sentinel events related to drug use. Data from the Medications Errors Reporting Program and U.S. Pharmacopeia (USP) MEDMARX data indicate that opioids, particularly morphine and hydromorphone, are among the most frequently confused drugs. This is associated with a high risk of patient harm when an error occurs. The Joint Commission has also developed patient safety goals focusing on safe drug administration. This includes simple measures such as being alert for drugs with similar names or appearances and through avoiding confusing abbreviations such as "QD" for "daily". All drugs administered to patients should be checked on admission and reviewed by the physician daily.

Alternatives to opioid therapy should also be considered where possible. A study suggested better pain relief with epidural bupivacaine over oral oxycodone in patients with peripheral arterial obstructive disease within the perioperative setting [122]. Although slightly impractical to apply across all patients due to the variation in route of administration, it can be a useful alternative to consider when opioid-sparing therapy is required.

The monitoring of opioid usage in chronic pain management poses a greater challenge. The number of opioid prescriptions has increased dramatically over the last twenty years, [123] most of which is prescribed for chronic noncancer pain [124]. Long-term opioid administration risks the development of tolerance. Cancer patients on chronic oral opioid therapy required a two- to three-fold increase in epidural opioid analgesia post-operatively to achieve similar levels of analgesia when compared to opioid-naïve patients [125]. The development of tolerance can be managed through changing the route of administration, drug structure or through antagonist-supported detoxification and a drug holiday from opioids [126-128]. Long-term opioid administration runs the risk of respiratory depression without adequate monitoring.

The American Pain Society - American Academy of Pain Medicine has recently published its guidelines for chronic opioid therapy [129]. It suggests that clinicians should periodically reassess patients on chronic opioid therapy. However, there is a lack of evidence on the appropriate monitoring intervals. Clinicians should therefore stratify patients according to risks for adverse outcomes to guide their approach towards monitoring. Patients with chronic pain at low risk could be monitored once every three to six months and more frequently for higher risk patients. The strongest predictive factor of drug abuse with opioid therapy is a history of previous alcohol or drug abuse $[130,131]$. The value of pre-existing pulmonary disease as a predictive factor for developing opioid-induced respiratory depression has yet to be evaluated [129].
Monitoring should include assessment of pain severity and current functional ability, current progress made towards agreed therapeutic goals, and the presence of any adverse effects [132]. Clinicians should also routinely assess for any drug abuse through periodic urine drug screening, pill counts, or family and patient interviews. Screening tools such as the Pain Assessment and Documentation Tool (PADT) and the Current Opioid Misuse Measure (COMM) have also been developed to assist the clinician, although there is no strong evidence supporting one over the other [129].

\section{Effective Treatment of Respiratory Depression is Available}

Respiratory side effects of opioids can be treated effectively. A decrease in respiratory rate ("oublie respiratoire") is an early sign of opioid-induced respiratory depression. This can be treated effectively once detected early. A variety of different strategies is appropriate according to severity: physical attempts to arouse the patient, administration of a opioid receptor antagonist, administration of respiratory stimulants, and/or by mechanical ventilation.

Depending on the degree of central nervous system depression, it might be possible to treat the opioid-induced respiratory depression by providing a constant stimulation to breathe. The clinician can try to arouse the patient by shaking and instructing him to breathe. The well established therapy for reversal of opioid-induced respiratory depression is the opioid receptor antagonist naloxone. However, reversing the effects of opioids via antagonism at the opioid receptors also has the undesirable effect of removing analgesia [133].

Recent studies have reported strong expression of 5$\mathrm{HT}_{4(\mathrm{a})}$ receptors within the pre-Bötzinger complex, and selective agonistic action can counteract fentanyl-induced respiratory depression whilst maintaining analgesia [134]. Several $5-\mathrm{HT}_{4(\mathrm{a})}$ agonists such as mosapride have already been shown to enhance activity in respiratory neurons in animal studies [133]. More recently, ampakines, which are positive modulators of the AMPA sub-type of glutamate receptors, have shown efficacy in reversing opioid-induced respiratory depression. This is thought to be both an effect of ampakines in regulating rhythmicity within the pre-Bötzinger complex [133] and in mediating excitatory transmission to the hypoglossal motoneurons responsible for maintain upper airway patency [135]. Finally, mechanical ventilation might be required to restore ventilation and gas-exchange in severely opioid-intoxicated patients.

\section{CONCLUSION}

Opioids induce a dose-dependent respiratory depression. This is caused through a combination of mechanisms - direct effect on the pre-Bötzinger and the RTN/pFRG complexes responsible for generating the respiratory pattern, dampening the response of both central and peripheral chemoreceptors to hypercapnia and hypoxia, and through increasing upper airway resistance and decreasing chest wall compliance via actions at the various motoneurons. However, there are many factors which modulate the individual's response to opioids such as intensity of postoperative pain, and other mecha- 
nisms leading to an increased stress response that may functionally antagonize opioid effects, as well as potentiating effects of non-opioid-anesthetics. The current challenge is for clinicians to avoid medication errors and titrate the opioid dose carefully, particularly when a new treatment is being initiated or if the pain stimulus decreases. It is required to effectively monitor for respiratory side effects, particularly in high-risk patients especially sensitive to the respiratory effects of opioids. Clinical treatment of opioid induced side effects is effective pending timely diagnosis and initiation of treatment.

Each institution needs to develop an optimal organization structure locally to define appropriate methods for avoiding medication errors, titrating opioids to target effect, and monitoring for respiratory side effects.

\section{REFERENCES}

[1] Chan PS, Krumholz HM, Nichol G, Nallamothu BK. Delayed time to defibrillation after in-hospital cardiac arrest. N Engl J Med 2008; 358(1): 9-17.

[2] Sandroni C, Nolan J, Cavallaro F, Antonelli M. In-hospital cardiac arrest: incidence, prognosis and possible measures to improve survival. Intensive Care Med 2007; 33(2): 237-45.

[3] Jacobi J, Fraser GL, Coursin DB, et al. Clinical practice guidelines for the sustained use of sedatives and analgesics in the critically ill adult. Crit Care Med 2002; 30(1): 119-41.

[4] Weinert CR, Kethireddy S, Roy S. Opioids and infections in the intensive care unit should clinicians and patients be concerned? J Neuroimmune Pharmacol 2008; 3(4): 218-29.

[5] Rose DK, Cohen MM, Wigglesworth DF, DeBoer DP. Critical respiratory events in the postanesthesia care unit. Patient, surgical, and anesthetic factors. Anesthesiology 1994; 81(2): 410-8.

[6] Chudnofsky CR, Wright SW, Dronen SC, Borron SW, Wright MB. The safety of fentanyl use in the emergency department. Ann Emerg Med 1989; 18(6): 635-9.

[7] Cashman JN, Dolin SJ. Respiratory and haemodynamic effects of acute postoperative pain management: evidence from published data. Br J Anaesth 2004; 93(2): 212-23.

[8] Rawal N, Arnér S, Gustafsson LL, Allvin R. Present state of extradural and intrathecal opioid analgesia in Sweden. A nationwide follow-up survey. Br J Anaesth 1987; 59(6): 791-9.

[9] Ready LB, Loper KA, Nessly M, Wild L. Postoperative epidural morphine is safe on surgical wards. Anesthesiology 1991; 75(3): 452-6.

[10] Wheatley RG, Madej TH, Jackson IJ, Hunter D. The first year's experience of an acute pain service. Br J Anaesth 1991; 67(3): 353-9.

[11] Fleming BM, Coombs DW. A survey of complications documented in a quality-control analysis of patient-controlled analgesia in the postoperative patient. J Pain Symp Manage 1992; 7(8): 463-9.

[12] Schug SA, Torrie JJ. Safety assessment of postoperative pain management by an acute pain service. Pain 1993; 55(3): 387-91.

[13] Sidebotham D, Dijkhuizen MR, Schug SA. The safety and utilization of patient-controlled analgesia. J Pain Symp Manage 1997; 14(4): 202-9.

[14] Byard RW, Gilbert JD. Narcotic administration and stenosing lesions of the upper airway--a potentially lethal combination. J Clin Forensic Med 2005; 12(1): 29-31

[15] Catley DM, Thornton C, Jordan C, Lehane JR, Royston D, Jones JG. Pronounced, episodic oxygen desaturation in the postoperative period: its association with ventilatory pattern and analgesic regimen. Anesthesiology 1985; 63(1): 20-8.

[16] Ciszkowski C, Madadi P, Phillips MS, Lauwers AE, Koren G. Codeine, ultrarapid-metabolism genotype, and postoperative death. N Engl J Med 2009; 361(8): 827-8.

[17] Gasche Y, Daali Y, Fathi M, et al. Codeine intoxication associated with ultrarapid CYP2D6 metabolism. N Engl J Med 2004; 351(27): 2827-31.
[18] Waldhoer M, Bartlett SE, Whistler JL. Opioid receptors. Annu Rev Biochem 2004: 73: 953-90.

[19] Sohn JT, Ok SH, Kim HJ, et al. Inhibitory effect of fentanyl on acetylcholine-induced relaxation in rat aorta. Anesthesiology 2004; 101(1): 89-96.

[20] Smith HS. Opioid metabolism. Mayo Clin Proc 2009; 84(7): 61324.

[21] Sarton E, Olofsen E, Romberg R, et al. Sex differences in morphine analgesia: an experimental study in healthy volunteers. Anesthesiology 2000; 93(5): 1245-54; discussion 6A.

[22] Dahan A, Sarton E, Teppema L, Olievier C. Sex-related differences in the influence of morphine on ventilatory control in humans. Anesthesiology 1998; 88(4): 903-13.

[23] Caraco Y, Sheller J, Wood AJ. Impact of ethnic origin and quinidine coadministration on codeine's disposition and pharmacodynamic effects. J Pharmacol Exp Ther 1999; 290(1): 413-22.

[24] Bathum L, Johansson I, Ingelman-Sundberg M, Hørder M, Brøsen $\mathrm{K}$. Ultrarapid metabolism of sparteine: frequency of alleles with duplicated CYP2D6 genes in a Danish population as determined by restriction fragment length polymorphism and long polymerase chain reaction. Pharmacogenetics 1998; 8(2): 119-23.

[25] Foster A, Mobley E, Wang Z. Complicated pain management in a CYP450 2D6 poor metabolizer. Pain Pract 2007; 7(4): 352-6.

[26] Desmeules J, Gascon MP, Dayer P, Magistris M. Impact of environmental and genetic factors on codeine analgesia. Eur J Clin Pharmacol 1991; 41(1): 23-6.

[27] Hasselström J, Eriksson S, Persson A, Rane A, Svensson JO, Säwe J. The metabolism and bioavailability of morphine in patients with severe liver cirrhosis. Br J Clin Pharmacol 1990; 29(3): 289-97.

[28] Milne RW, Nation RL, Somogyi AA, Bochner F, Griggs WM. The influence of renal function on the renal clearance of morphine and its glucuronide metabolites in intensive-care patients. $\mathrm{Br} \mathrm{J}$ Clin Pharmacol 1992; 34(1): 53-9.

[29] Pauli-Magnus C, Hofmann U, Mikus G, Kuhlmann U, Mettang T. Pharmacokinetics of morphine and its glucuronides following intravenous administration of morphine in patients undergoing continuous ambulatory peritoneal dialysis. Nephrol Dial Transplant 1999; 14(4): 903-9.

[30] Angst MS, Bührer M, Lötsch J. Insidious intoxication after morphine treatment in renal failure: delayed onset of morphine-6glucuronide action. Anesthesiology 2000; 92(5): 1473-6.

[31] Foral PA, Ineck JR, Nystrom KK. Oxycodone accumulation in a hemodialysis patient. South Med J 2007; 100(2): 212-4.

[32] Bodd E, Jacobsen D, Lund E, Ripel A, Mørland J, Wiik-Larsen E. Morphine-6-glucuronide might mediate the prolonged opioid effect of morphine in acute renal failure. Hum Exp Toxicol 1990; 9(5): $317-21$.

[33] Talbott GA, Lynn AM, Levy FH, Zelikovic I. Respiratory arrest precipitated by codeine in a child with chronic renal failure. Clin Pediatr (Phila) 1997; 36(3): 171-3.

[34] Fitzgerald J. Narcotic analgesics in renal failure. Conn Med 1991; 55(12): 701-4.

[35] Haberer JP, Schoeffler P, Couderc E, Duvaldestin P. Fentanyl pharmacokinetics in anaesthetized patients with cirrhosis. Br J Anaesth 1982; 54(12): 1267-70.

[36] Novick DM, Kreek MJ, Fanizza AM, Yancovitz SR, Gelb AM, Stenger RJ. Methadone disposition in patients with chronic liver disease. Clin Pharmacol Ther. 1981; 30(3): 353-62.

[37] Fritz HG, Holzmayr M, Walter B, Moeritz KU, Lupp A, Bauer R. The effect of mild hypothermia on plasma fentanyl concentration and biotransformation in juvenile pigs. Anesth Analg 2005; 100(4): 996-1002.

[38] Fritz HG, Bauer R. Secondary injuries in brain trauma: effects of hypothermia. J Neurosurg Anesthesiol 2004; 16: 43-52.

[39] Hindman BJ, Todd MM, Gelb AW, et al. Mild hypothermia as a protective therapy during intracranial aneurysm surgery: a randomized prospective pilot trial. Neurosurgery 1999; 44(1): 2332. discussion 32-3.

[40] Soliman HM, Melot C, Vincent JL. Sedative and analgesic practice in the intensive care unit: the results of a European survey. $\mathrm{Br} \mathrm{J}$ Anaesth 2001; 87: 186-92. 
[41] Nieuwenhuijs DJ, Olofsen E, Romberg RR, et al. Response surface modeling of remifentanil-propofol interaction on cardiorespiratory control and bispectral index. Anesthesiology 2003; 98(2): 312-22.

[42] Dahan A, Nieuwenhuijs D, Olofsen E, Sarton E, Romberg R, Teppema $\mathrm{L}$. Response surface modeling of alfentanil-sevoflurane interaction on cardiorespiratory control and bispectral index. Anesthesiology 2001; 94(6): 982-91.

[43] Chawla G, Drummond GB. Fentanyl decreases end-expiratory lung volume in patients anaesthetized with sevoflurane. Br J Anaesth 2008; 100(3): 411-4.

[44] Pattinson KT. Opioids and the control of respiration. Br J Anaesth 2008; 100(6): 747-58

[45] Ho AM, Chen S, Karmakar MK. Central apnoea after balanced general anaesthesia that included dexmedetomidine. Br J Anaesth 2005; 95(6): 773-5.

[46] Gueye PN, Borron SW, Risède $\mathrm{P}$, et al. Buprenorphine and midazolam act in combination to depress respiration in rats. Toxicol Sci 2002; 65(1): 107-14.

[47] Bianchi AL, Denavit-Saubié M, Champagnat J. Central control of breathing in mammals: neuronal circuitry, membrane properties, and neurotransmitters. Physiol Rev 1995; 75(1): 1-45.

[48] Richter DW, Spyer KM. Studying rhythmogenesis of breathing: comparison of in vivo and in vitro models. Trends Neurosci 2001; 24(8): 464-72.

[49] Feldman JL, Del Negro CA. Looking for inspiration: new perspectives on respiratory rhythm. Nat Rev Neurosci 2006; 7(3): $232-42$.

[50] Smith JC, Ellenberger HH, Ballanyi K, Richter DW, Feldman JL. Pre-Bötzinger complex: a brainstem region that may generate respiratory rhythm in mammals. Science 1991; 254(5032): 726-9.

[51] Rybak IA, Shevtsova NA, Ptak K, McCrimmon DR. Intrinsic bursting activity in the pre-Bötzinger complex: role of persistent sodium and potassium currents. Biol Cybern 2004; 90(1): 59-74.

[52] Johnson SM, Smith JC, Funk GD, Feldman JL. Pacemaker behavior of respiratory neurons in medullary slices from neonatal rat. $\mathrm{J}$ Neurophysiol 1994; 72(6): 2598-608.

[53] Del Negro CA, Morgado-Valle C, Hayes JA, et al. Sodium and calcium current-mediated pacemaker neurons and respiratory rhythm generation. J Neurosci 2005; 25(2): 446-53.

[54] Peña F, Parkis MA, Tryba AK, Ramirez JM. Differential contribution of pacemaker properties to the generation of respiratory rhythms during normoxia and hypoxia. Neuron 2004; 43(1): 105-17.

[55] Onimaru H, Homma I. A novel functional neuron group for respiratory rhythm generation in the ventral medulla. J Neurosci 2003; 23(4): 1478-86.

[56] Feldman JL, Mitchell GS, Nattie EE. Breathing: rhythmicity, plasticity, chemosensitivity. Annu Rev Neurosci 2003; 26: 239-66.

[57] Guyenet PG, Mulkey DK. Retrotrapezoid nucleus and parafacial respiratory group. Respir Physiol Neurobiol 2010; 173(3): 244-55.

[58] Gray PA, Rekling JC, Bocchiaro CM, Feldman JL. Modulation of respiratory frequency by peptidergic input to rhythmogenic neurons in the preBötzinger complex. Science 1999; 286(5444): 1566-8.

[59] Shook JE, Watkins WD, Camporesi EM. Differential roles of opioid receptors in respiration, respiratory disease, and opiateinduced respiratory depression. Am Rev Respir Dis 1990; 142(4): 895-909.

[60] Sales N, Riche D, Roques BP, Denavit-Saubie M. Localization of mu- and delta-opioid receptors in cat respiratory areas: an autoradiographic study. Brain Res 1985; 344(2): 382-6.

[61] Montandon G, Qin W, Liu H, Ren J, Greer JJ, Horner RL. PreBotzinger complex neurokinin-1 receptor-expressing neurons mediate opioid-induced respiratory depression. J Neurosci 2011; 31(4): 1292-301.

[62] Chamberlin NL, Saper CB. Topographic organization of respiratory responses to glutamate microstimulation of the parabrachial nucleus in the rat. J Neurosci 1994; 14(11 Pt 1): 6500-10.

[63] Alheid GF, Milsom WK, McCrimmon DR. Pontine influences on breathing: an overview. Respir Physiol Neurobiol 2004; 143(2-3): 105-14.
[64] Mörschel M, Dutschmann M. Pontine respiratory activity involved in inspiratory/expiratory phase transition. Philos Trans R Soc Lond B Biol Sci 2009; 364(1529): 2517-26.

[65] Lalley PM. Opiate slowing of feline respiratory rhythm and effects on putative medullary phase-regulating neurons. Am J Physiol Regul Integr Comp Physiol 2006; 290(5): R1387-96.

[66] Pattinson KT, Governo RJ, MacIntosh BJ, et al. Opioids depress cortical centers responsible for the volitional control of respiration. J Neurosci 2009; 29(25): 8177-86.

[67] Lydic R, Baghdoyan HA. Sleep, anesthesiology, and the neurobiology of arousal state control. Anesthesiology 2005; 103(6): 1268-95.

[68] Schwartz RS, Brown EN, Lydic R, Schiff ND. General anesthesia, sleep, and coma. N Engl J Med 2010; 363(27): 2638-50.

[69] Kubin L, Alheid GF, Zuperku EJ, McCrimmon DR. Central pathways of pulmonary and lower airway vagal afferents. J Appl Physiol 2006; 101(2): 618-27.

[70] Poole SL, Deuchars J, Lewis DI, Deuchars SA. Subdivisionspecific responses of neurons in the nucleus of the tractus solitarius to activation of mu-opioid receptors in the rat. J Neurophysiol 2007; 98(5): 3060-71.

[71] Oyamada Y, Ballantyne D, Mückenhoff K, Scheid P. Respirationmodulated membrane potential and chemosensitivity of locus coeruleus neurones in the in vitro brainstem-spinal cord of the neonatal rat. J Physiol 1998; 513 (Pt 2): 381-98.

[72] Janczewski WA, Feldman JL. Distinct rhythm generators for inspiration and expiration in the juvenile rat. J Physiol 2006; 570(Pt 2): 407-20

[73] Mulkey DK, Stornetta RL, Weston MC, et al. Respiratory control by ventral surface chemoreceptor neurons in rats. Nat Neurosci 2004; 7(12): 1360-9.

[74] Buchanan GF, Richerson GB. Role of chemoreceptors in mediating dyspnea. Respir Physiol Neurobiol 2009; 167(1): 9-19.

[75] Richerson GB. Serotonergic neurons as carbon dioxide sensors that maintain $\mathrm{pH}$ homeostasis. Nat Rev Neurosci 2004; 5(6): 449-61.

[76] Nattie E. CO2, brainstem chemoreceptors and breathing. Prog Neurobiol 1999; 59(4): 299-331.

[77] Nattie EE, Li A. CO2 dialysis in the medullary raphe of the rat increases ventilation in sleep. J Appl Physiol 2001; 90(4): $1247-57$.

[78] McMullan S, Pilowsky PM. The effects of baroreceptor stimulation on central respiratory drive: A review. Respir Physiol Neurobiol 2010; 174(1-2): 37-42.

[79] Rosenblum MG, Cimponeriu L, Bezerianos A, Patzak A, Mrowka R. Identification of coupling direction: application to cardiorespiratory interaction. Phys Rev E Stat Nonlin Soft Matter Phys 2002; 65(4 Pt 1): 041909

[80] Schäfer C, Rosenblum MG, Kurths J, Abel HH. Heartbeat synchronized with ventilation. Nature 1998; 392(6673): 239-40.

[81] Wu SD, Lo PC. Cardiorespiratory phase synchronization during normal rest and inward-attention meditation. Int $\mathrm{J}$ Cardiol 2010; 141(3): 325-8.

[82] Bailey PL, Lu JK, Pace NL, et al. Effects of intrathecal morphine on the ventilatory response to hypoxia. N Engl J Med 2000; 343(17): 1228-34.

[83] Teichtahl $\mathrm{H}$, Wang $\mathrm{D}$, Cunnington $\mathrm{D}$, et al. Ventilatory responses to hypoxia and hypercapnia in stable methadone maintenance treatment patients. Chest 2005; 128(3): 1339-47.

[84] Ward SL, Bautista D, Chan L, et al. Sudden infant death syndrome in infants of substance-abusing mothers. J Pediatr 1990; 117(6): 876-81.

[85] Zhang Z, Xu F, Zhang C, Liang X. Activation of opioid mu receptors in caudal medullary raphe region inhibits the ventilatory response to hypercapnia in anesthetized rats. Anesthesiology 2007; 107(2): 288-97.

[86] Dahan A, Sarton E, van den Elsen M, van Kleef J, Teppema L, Berkenbosch A. Ventilatory response to hypoxia in humans. Influences of subanesthetic desflurane. Anesthesiology 1996; 85(1): 60-8.

[87] McQueen DS, Ribeiro JA. Inhibitory actions of methionineenkephalin and morphine on the cat carotid chemoreceptors. Br J Pharmacol 1980; 71(1): 297-305. 
[88] White DP. Pathogenesis of obstructive and central sleep apnea. Am J Respir Crit Care Med 2005; 172(11): 1363-70.

[89] Schwartz AR, Smith PL, Wise RA, Gold AR, Permutt S. Induction of upper airway occlusion in sleeping individuals with subatmospheric nasal pressure. J Appl Physiol 1988; 64(2): 535-42.

[90] Schwartz AR, Gold AR, Schubert N, et al. Effect of weight loss on upper airway collapsibility in obstructive sleep apnea. Am Rev Respir Dis 1991; 144(3 Pt 1): 494-8.

[91] Isono S, Remmers JE, Tanaka A, Sho Y, Sato J, Nishino T. Anatomy of pharynx in patients with obstructive sleep apnea and in normal subjects. J Appl Physiol 1997; 82(4): 1319-26.

[92] Watanabe T, Isono S, Tanaka A, Tanzawa H, Nishino T. Contribution of body habitus and craniofacial characteristics to segmental closing pressures of the passive pharynx in patients with sleepdisordered breathing. Am J Respir Crit Care Med 2002; 165(2): 260-5.

[93] Sauerland EK, Mitchell SP. Electromyographic activity of the human Genioglossus muscle in response to respiration and to positional changes of the head. Bull Los Angeles Neurol Soc 1970; 35(2): 69-73.

[94] Chamberlin NL, Eikermann M, Fassbender P, White DP, Malhotra A. Genioglossus premotoneurons and the negative pressure reflex in rats. J Physiol 2007; 579(Pt 2): 515-26.

[95] Kobayashi I, Perry A, Rhymer J, et al. Inspiratory coactivation of the genioglossus enlarges retroglossal space in laryngectomized humans. J Appl Physiol 1996; 80(5): 1595-1604.

[96] Oliven A, O'Hearn DJ, Boudewyns A, et al. Upper airway response to electrical stimulation of the genioglossus in obstructive sleep apnea. J Appl Physiol 2003; 95(5): 2023-9.

[97] White DP. Opioid-induced suppression of genioglossal muscle activity: is it clinically important? J Physiol 2009; 587(Pt 14): 3421-2.

[98] Herbstreit F, Zigrahn D, Ochterbeck C, Peters J, Eikermann M. Neostigmine/Glycopyrrolate administered after recovery from neuromuscular block increases upper airway collapsibility by decreasing genioglossus muscle activity in response to negative pharyngeal pressure. Anesthesiology 2010; 113(6): 1280-8.

[99] Mezzanotte WS, Tangel DJ, White DP: Waking genioglossal electromyogram in sleep apnea patients versus normal controls (a neuromuscular compensatory mechanism). J Clin Invest 1992; 89: 1571-9

[100] Hajiha M, DuBord MA, Liu H, Horner RL. Opioid receptor mechanisms at the hypoglossal motor pool and effects on tongue muscle activity in vivo. J Physiol 2009; 587(Pt 11): 2677-92.

[101] Lalley PM. Mu-opioid receptor agonist effects on medullary respiratory neurons in the cat: evidence for involvement in certain types of ventilatory disturbances. Am J Physiol Regul Integr Comp Physiol 2003; 285(6): R1287-304.

[102] Zebraski SE, Kochenash SM, Raffa RB. Lung opioid receptors: pharmacology and possible target for nebulized morphine in dyspnea. Life Sci 2000; 66(23): 2221-31.

[103] Ruiz Neto PP, Auler Júnior JO. Respiratory mechanical properties during fentanyl and alfentanil anaesthesia. Can J Anaesth 1992; 39(5 Pt 1): 458-65.

[104] Horrow JC, Abrams JT, Van Riper DF, Lambson DL, Storella RJ. Ventilatory compliance after three sufentanil-pancuronium induction sequences. Anesthesiology 1991; 75(6): 969-74.

[105] Lui PW, Lee TY, Chan SH. Involvement of coerulospinal noradrenergic pathway in fentanyl-induced muscular rigidity in rats. Neurosci Lett 1990; 108(1-2): 183-8.

[106] Campbell C, Weinger MB, Quinn M. Alterations in diaphragm EMG activity during opiate-induced respiratory depression. Respir Physiol 1995; 100(2): 107-17.

[107] Chung SA, Yuan H, Chung F. A systemic review of obstructive sleep apnea and its implications for anesthesiologists. Anesth Analg 2008; 107(5): 1543-63.

[108] Eastwood PR, Szollosi I, Platt PR, Hillman DR: Comparison of upper airway collapse during general anaesthesia and sleep. Lancet 2002; 359: 1207-9

[109] Robinson RW, Zwillich CW, Bixler EO, Cadieux RJ, Kales A, White DP. Effects of oral narcotics on sleep-disordered breathing in healthy adults. Chest 1987; 91(2): 197-203.
[110] Brown KA, Laferrière A, Moss IR. Recurrent hypoxemia in young children with obstructive sleep apnea is associated with reduced opioid requirement for analgesia. Anesthesiology 2004; 100(4): 806-10. discussion 5A.

[111] Lamarche Y, Martin R, Reiher J, Blaise G. The sleep apnoea syndrome and epidural morphine. Can Anaesth Soc J 1986; 33(2): 231-3.

[112] Ostermeier AM, Roizen MF, Hautkappe M, Klock PA, Klafta JM. Three sudden postoperative respiratory arrests associated with epidural opioids in patients with sleep apnea. Anesth Analg 1997; 85(2): 452-60.

[113] Cullen DJ. Obstructive sleep apnea and postoperative analgesia--a potentially dangerous combination. J Clin Anesth 2001; 13(2): 835.

[114] Reeder MK, Goldman MD, Loh L, Muir AD, Casey KR, Gitlin DA. Postoperative obstructive sleep apnoea. Haemodynamic effects of treatment with nasal CPAP. Anaesthesia 1991; 46(10): 849-53.

[115] Gross JB, Bachenberg KL, Benumof JL, et al. Practice guidelines for the perioperative management of patients with obstructive sleep apnea: a report by the American Society of Anesthesiologists Task Force on Perioperative Management of patients with obstructive sleep apnea. Anesthesiology 2006; 104(5): 1081-93. quiz 1117-8.

[116] Shapiro A, Zohar E, Zaslansky R, Hoppenstein D, Shabat S, Fredman B. The frequency and timing of respiratory depression in 1524 postoperative patients treated with systemic or neuraxial morphine. J Clin Anesth 2005; 17(7): 537-42.

[117] Sveticic G, Eichenberger U, Curatolo M. Safety of mixture of morphine with ketamine for postoperative patient-controlled analgesia: an audit with 1026 patients. Acta Anaesthesiol Scand 2005; 49(6): $870-5$

[118] Lalley PM. Opioidergic and dopaminergic modulation of respiration. Respir Physiol Neurobiol 2008; 164: 160-7.

[119] Flisberg P, Rudin A, Linnér R, Lundberg CJ. Pain relief and safety after major surgery. A prospective study of epidural and intravenous analgesia in 2696 patients. Acta Anaesthesiol Scand 2003; 47(4): 457-65.

[120] Rygnestad T, Borchgrevink PC, Eide E. Postoperative epidural infusion of morphine and bupivacaine is safe on surgical wards. Organisation of the treatment, effects and side-effects in 2000 consecutive patients. Acta Anaesthesiol Scand 1997; 41(7): 868-76.

[121] de Leon-Casasola OA, Parker B, Lema MJ, Harrison P, Massey J. Postoperative epiduralbupivacaine-morphine therapy. Experience with 4,227 surgical cancer patients. Anesthesiology 1994; 81(2): 368-75.

[122] Samolsky Dekel BG, Melotti RM, Gargiulo M, Freyrie A, Stella A, Di Nino G. Pain management in peripheral arterial obstructive disease: oral slow-release oxycodone versus epidural 1-bupivacaine. Eur J Vasc Endovasc Surg 2010; 39(6): 774-8.

[123] Olsen Y, Daumit GL, Ford DE. Opioid prescriptions by U.S. primary care physicians from 1992 to 2001. J Pain 2006; 7(4): 225-35.

[124] Sullivan MD, Edlund MJ, Fan MY, Devries A, Brennan Braden J, Martin BC. Trends in use of opioids for non-cancer pain conditions 2000-2005 in commercial and Medicaid insurance plans: the TROUP study. Pain 2008; 138(2): 440-9.

[125] de Leon-Casasola OA, Myers DP, Donaparthi S, et al. A comparison of postoperative epidural analgesia between patients with chronic cancer taking high doses of oral opioids versus opioidnaive patients. Anesth Analg 1993; 76(2): 302-7.

[126] Breitfeld C, Eikermann M, Kienbaum P, Peters J. Opioid "holiday" following antagonist supported detoxification during general anesthesia improves opioid agonist response in a cancer patient with opioid addiction. Anesthesiology 2003; 98(2): 571-3.

[127] McQuay H. Opioids in pain management. Lancet 1999; 353: 2229-32.

[128] De Leon-Casasola OA, Lema MJ. Epidural bupivacaine/sufentanil therapy for postoperative pain control in patients tolerant to opioid and unresponsive to epidural bupivacaine/morphine. Anesthesiology 1994; 80: 303-9.

[129] Chou R, Fanciullo GJ, Fine PG, et al. Clinical guidelines for the use of chronic opioid therapy in chronic noncancer pain. J Pain 2009; 10(2): 113-30. 
[130] Edlund MJ, Steffick D, Hudson T, Harris KM, Sullivan M. Risk factors for clinically recognized opioid abuse and dependence among veterans using opioids for chronic non-cancer pain. Pain 2007; 129(3): 355-62.

[131] Michna E, Ross EL, Hynes WL, et al. Predicting aberrant drug behavior in patients treated for chronic pain: importance of abuse history. J Pain Symptom Manage 2004; 28(3): 250-8.

[132] Passik SD, Kirsh KL, Whitcomb L, et al. A new tool to assess and document pain outcomes in chronic pain patients receiving opioid therapy. Clin Ther 2004; 26(4): 552-61.
[133] Dahan A, Aarts L, Smith TW. Incidence, Reversal, and Prevention of Opioid-induced Respiratory Depression. Anesthesiology 2010; 112(1): 226-38.

[134] Manzke T, Guenther U, Ponimaskin EG, et al. 5-HT4(a) receptors avert opioid-induced breathing depression without loss of analgesia. Science 2003; 301(5630): 226-9.

[135] Lorier AR, Funk GD, Greer JJ. Opiate-induced suppression of rat hypoglossal motoneuron activity and its reversal by ampakine therapy. PLoS One 2010; 5(1): e8766.

(C) Koo and Eikermann; Licensee Bentham Open

This is an open access article licensed under the terms of the Creative Commons Attribution Non-Commercial License (http://creativecommons.org/licenses/ by-nc/3.0/) which permits unrestricted, non-commercial use, distribution and reproduction in any medium, provided the work is properly cited. 